\title{
Structural Interpretations Inferred from a High Resolution Aeromagnetic (HRAM) Data over Parts of Onshore Niger Delta, Nigeria
}

\author{
Bello Rasaq ${ }^{*}$, Ofoha Chimezie Charles \\ Department of Physics, University of Port Harcourt, Choba, Nigeria \\ Email address: \\ bellomo68@yahoo.com (B. Rasaq) \\ ${ }^{*}$ Corresponding author
}

To cite this article:

Bello Rasaq, Ofoha Chimezie Charles. Structural Interpretations Inferred from a High Resolution Aeromagnetic (HRAM) Data over Parts of Onshore Niger Delta, Nigeria. International Journal of High Energy Physics. Vol. 4, No. 3, 2017, pp. 23-31.

doi: $10.11648 /$ j.ijhep.20170403.11

Received: June 3, 2017; Accepted: June 29, 2017; Published: August 15, 2017

\begin{abstract}
Aeromagnetic data acquired by the Nigerian Geological Survey Agency (NGSA) and which covers about 3025 square kilometer of some parts of onshore Niger Delta, Nigeria, was processed and interpreted with the purpose of highlighting the structural lineaments with their corresponding trend patterns and then inferring the effect of the structures as it relates to the hydrocarbon potential and tectonic history of the area using the qualitative approach. Using polynomial fitting of degree two (2), regional - residual separation was carried out on the Composite Total Magnetic Intensity (CTMI) map, lying geographically within longitude $6^{\circ} 30^{\prime} \mathrm{E}-7^{\circ} 0^{\prime} 0^{\prime \prime} \mathrm{E}$ and latitude $4^{\circ} 30^{\prime} \mathrm{N}-5^{\circ} 0^{\prime} 0^{\prime \prime}$, and this generated the regional and residual maps. Some enhancement techniques applied upon the residual map gave rise to some directional gradient maps that depicted structural lineaments trending in the E - W, NE - SW, NW - SE and N - S directions. These lineaments influence the tectonics of the area and as such created faults and fractures that fostered the migration and entrapment of hydrocarbon, and perhaps mineral, within the area under review.
\end{abstract}

Keywords: Lineaments, Polynomial Fitting, Migration, Concealment, Olobiri, Degema

\section{Introduction}

The aim of magnetic survey is to investigate subsurface geology on the basis of magnetic anomalies in the earth's magnetic field resulting from the magnetic properties of the underlying rocks [1]. The magnetic method is a passive geophysical method [2]. By being passive, no energy source is needed in order to acquire data [3]. Magnetic survey can be performed on land, at sea and in air. When performed in air an aeromagnetic study is undertaken and as such a magnetometer is towed behind an aircraft. Aeromagnetic survey has become an indispensable component of exploration programmes in areas where exposure is poor [4]. [5] stated that the speed of operation and low number of field personnel's make magnetic surveys performed either on land, at sea and in the air, very attractive. They further explained that the main objective has been to assist in mineral and hydrocarbon exploration through improved geologic mapping. The magnetic method measures spatial variations in the earth's magnetic fields. Changes in the earth's magnetic are caused by variations in rock magnetism, which is mostly controlled by a physical property called magnetic susceptibility [4]. [6] pointed out that this variation in the magnetic susceptibility can cause small magnetic variation in the magnetic fields of rocks measured on the surface. Generally, the susceptibility of rocks varies and this depends on the type of rock and the environment it is in. Magnetic surveys, usually in nano tesla (nT), indicate that there are many unexpected variations in this model, called "magnetic anomalies" and this could be caused by dykes, faults and lava flows. Nevertheless, anomalies in the earth's magnetic field are caused by induced or remnant magnetism. Induced magnetic anomalies are the result of secondary magnetization induced in a ferrous body by the earth's magnetic field. The shape, dimensions and amplitude of an induced magnetic anomaly is a function of the orientation, geometry, size, 
depth, and magnetic susceptibility of the body as well as the intensity and inclination of the earth's magnetic field in the survey area [1]. Aeromagnetic field data play important role in delineating geological features for hydrocarbon exploration. Magnetic surveys are often undertaken prior to seismic surveys with the aim of delineating structural trend lineaments, so that seismic surveys can be designed in a cost effective manner for maximum result [7].

The Niger Delta province is ranked among the major prolific deltaic hydrocarbon provinces in the world and is the most significant in the West African continental margin. Oil and gas in the Niger Delta are principally produced from sandstones and unconsolidated sands predominantly in the Agbada Formation [8]. Niger Delta basin is known specifically, all over the world, for its hydrocarbon potential. So researchers, government as well as oil exploration companies have made attempts towards the exploration of its hydrocarbon, and perhaps mineral, potentials. Thus, extensive researches have been carried out, and are also currently ongoing, within the basin with various aims and objectives. [9] enunciated that majority of the exploration works in the Niger delta have been concentrated on the seismic survey of Tertiary deltaic hydrocarbon bearing sequence with little or no attention paid to the underlying basement structures. The knowledge of basement framework has been known to exert significant control on the structural disposition and petroleum system of the overlying sedimentary section, according to [9]. [10] asserted that, in thick sedimentary terrain like the Niger delta basin, regional aeromagnetic field data sets can be utilized in imaging the basement under the sedimentary section, particularly if magnetic sources within the sedimentary section are weaker than the basement rocks as this will have control on the hydrocarbon bearing potential of the basin since structures which will enhance the migration and entrapment of hydrocarbon and minerals will be exhumed. According to [10], important factors such as regional structural characteristics of the basement and the relationship between deep basement architecture and hydrocarbon target have been lacking in the delta.

Thus, with the vision of contributing to the basin modeling, ascertaining the production capability and unraveling the structural controls in terms of hydrocarbon and mineral potential of the study area, this study was undertaken.

Location and Geology of the Study Area

The study area (Figure 1) is bounded eastwards by Port Harcourt, westwards by Oloibiri, southwards by Rule and Bony and Northwards by Patani and Ahoada. The study area lies between longitude $6^{\circ} 30^{\prime} \mathrm{E}-7^{\circ} 0^{\prime} 0^{\prime \prime} \mathrm{E}$ and latitude $4^{\circ} 30^{\prime} \mathrm{N}$ $5^{\circ} 0^{\prime} 0$ "with an approximate area of about $3025 \mathrm{~km}^{2}$ within the Niger Delta sedimentary basin of Nigeria. The geologic map, (Figure 2), reveals the area to be swampy and also depicts the Creeks, Benin Formation and Sombreiro Warri Deltaic Plain, SDP.

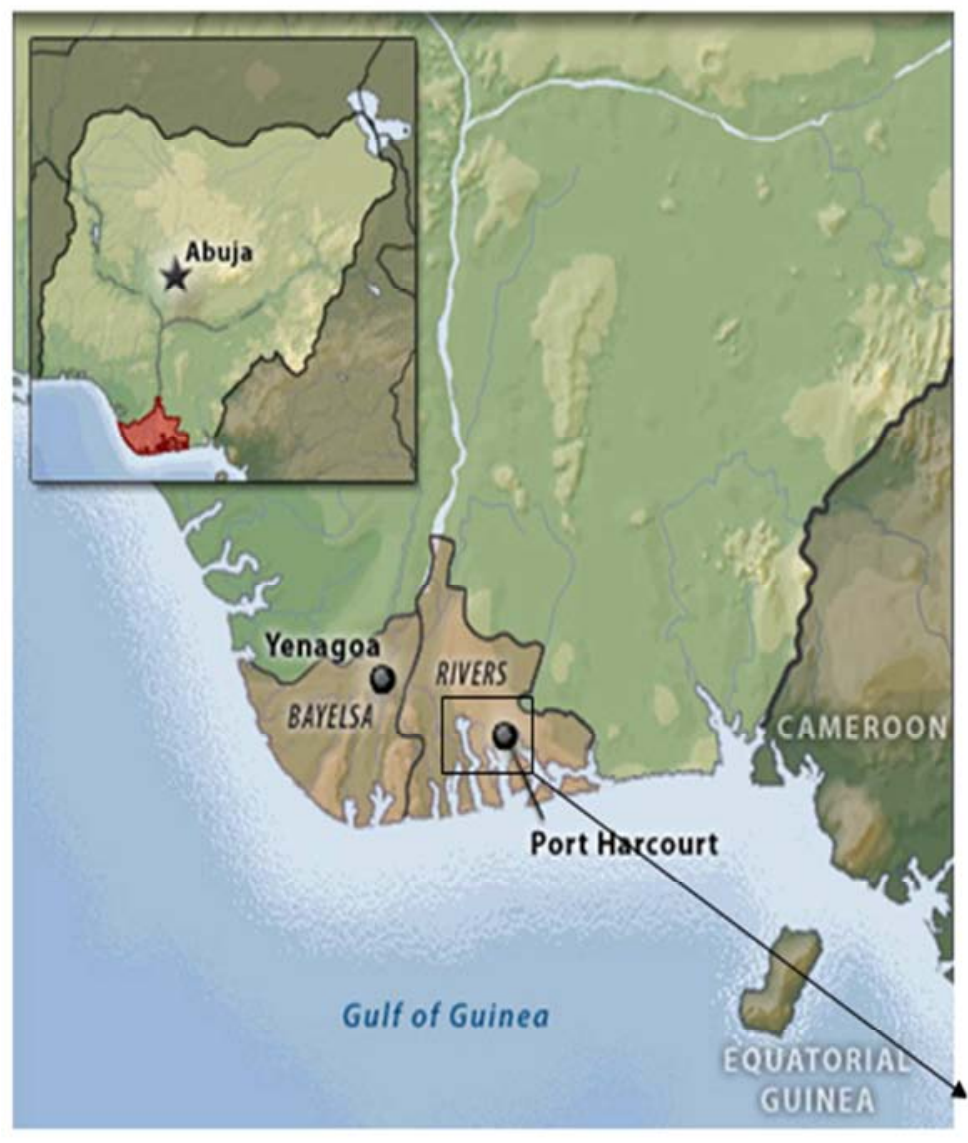




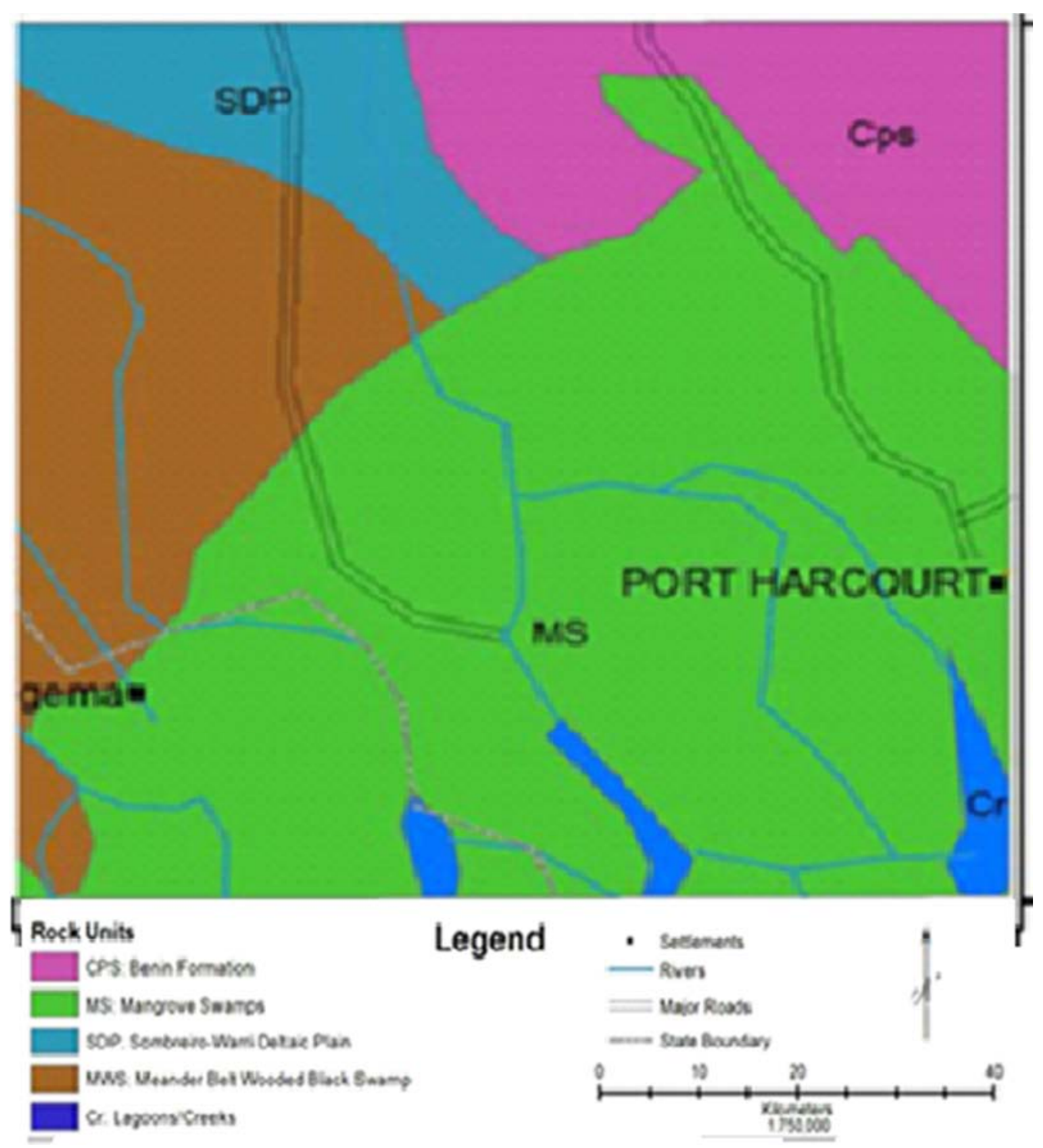

Figure 2. Geological Map of the Study Area (Obtained from the Nigerian Geological Survey Agency, NGSA, Abuja).

\section{Materials and Methods}

The data used for this study is a digitized aeromagnetic data (Figure 3) obtained from the Nigerian Geological Survey Agency (NGSA) Abuja on a scale of 1:100000 in half degree sheet. The aeromagnetic data, comprising of sheet 328 and which covers the Degema province, Rivers State, Nigeria was part of Phase II project carried by Fugro Airborne Surveys between 2007 and 2010 on behalf of the NGSA. The aeromagnetic survey was flown at $500 \mathrm{~m}$ line spacing, tie line of $2 \mathrm{~km}$ and $80 \mathrm{~m}$ mean terrain clearance. Oasis Montaj 6.4.2 (Geosoft) software was used for the data processing, analysis and interpretation.

Enhancement Techniques Applied on the Data

Data enhancement techniques include numerical algorithms operating on the survey data (Michael and Steven, 2014). For this study, this algorithm involves filtering actions which were carried out basically to enhance characteristics of the signatures that are considered particularly significant. To achieve the purpose of this research which is aimed at identifying structures within the study area, the following enhancement techniques were applied on the aeromagnetic data obtained in spread sheet file format:

Regional - Residual Separation

[12] stated that magnetic data obtained during a magnetometer survey is a sum total of the magnetic effect from the underground sources and that the usual targets in a magnetic survey are the high wave number components (or the residuals) buried at shallow depths. The magnetic responses due to residuals are often embedded in a regional field seated farther away from the residuals or the shallow magnetic bodies. They went further by stating that Interpretation and numerical modeling are carried out on the residual field data, and the reliability of the interpretation depends to a great extent upon the success of the regional - residual separation targets. Hence, the need for this study to apply regional - residual separation on the aeromagnetic data using the grid and image module of the Oasis Montaj software. Polynomial fitting of degree two (2) 
was applied on the total magnetic intensity (TMI) map for the deep seated structures to be separated from the shallow structures.

\section{First Vertical Derivative (FVD)}

FVD was applied on the residual map in order to sharpenup anomalies and allow clearer imaging of the shallow causative structures vertically. This filtering technique enhanced high frequency components at the expense of low frequency components which were deeply seated. The FVD has been a standard in computing high frequency features using the Laplace transformation expressions shown below:

$$
\Delta^{2} \mathrm{f}=0
$$

Where $\Delta^{2} \mathrm{f}$ is the Laplace transform which can be expressed $\mathrm{i}$ $\mathrm{n}$ full as

$$
\frac{\partial^{2} f}{\partial z^{2}}=-\left[\frac{\partial^{2} f}{\partial x^{2}}+\frac{\partial^{2} f}{\partial x 2}\right]
$$

$\partial z, \partial y$ and $\partial x$ are the differentials in $\mathrm{z}, \mathrm{y}$ and $\mathrm{x}$ cordinates

Then nth vertical derivative can be computed once the Fourier transform is known by using the equation shown below:

$$
\mathrm{F}\left[\boldsymbol{\partial}^{\mathrm{n}} \mathrm{f} / \boldsymbol{\partial} \mathrm{z}^{\mathrm{n}}\right]=\mathrm{K}^{\mathrm{n}} \cdot \mathrm{F}(\mathrm{f})
$$

Where

$\mathrm{F}$ is the Fourier representation of the field

$\mathrm{k}$ is the wave number or frequency.

$\mathrm{f}$ is the input to be filtered.

Second Vertical Derivative (SVD)

Likethe FVD, the SVD enhances the shallow seated sources, and makes it to appear vertical, at the expense of the deeply seated bodies. Shallow bodies or the high wave number components were apparent when SVD was applied on the residual map. This filtering technique is based on equation 3 but when $\mathrm{n}=2$

First Horizontal Derivative (FHD)

The horizontal derivative is a measure of how much the earth's magnetic field changes with respect to horizontal direction. The FHD when applied on the residual map enhanced shallow anomalous features in the lateral or horizontal directions. According to [13] the biggest advantage of the horizontal gradient method is the low degree of noise in the data. This form of filtering technique enhanced the edges of magnetic bodies.

[14] believes that, in Fourier domain, the horizontal derivatives of a smoothly scalar quantity $\varnothing(x, y)$, in $x$ and $y$ directions are given by:

$$
\begin{gathered}
\mathrm{F}\left[\mathrm{d}^{\mathrm{n}} \varnothing / \mathrm{dx}^{\mathrm{n}}\right]=\left(i \mathrm{k}_{\mathrm{x}}\right)^{\mathrm{n}} \mathrm{F}(\emptyset) \\
\mathrm{F}\left[\frac{d^{n} \varnothing}{d y^{n}}\right]=\left(i k_{y}\right)^{n} \mathrm{~F}(\emptyset)
\end{gathered}
$$

Where the factorsand are operators which transforms a function into $\mathrm{nth}$ order derivatives with respect to $\mathrm{x}$ and $\mathrm{y}$, respectively [15]

\section{Results and Interpretation}

The colour (raster) map (Figure 3) was transformed into a contour map (Figure 4). Colour variations and different contour configurations are discernible on the raster and contour maps. Negative and positive magnetic values are evident on the maps. The negative values are indicative of magnetically quiet regions while the positive values are indicative of areas that are magnetically responsive. The TMI values range from- $55 \mathrm{nT}$ to $5.5 \mathrm{nT}$ for the magnetic low and from $19.4 \mathrm{nT}$ to $90.7 \mathrm{nT}$ for the magnetic high.
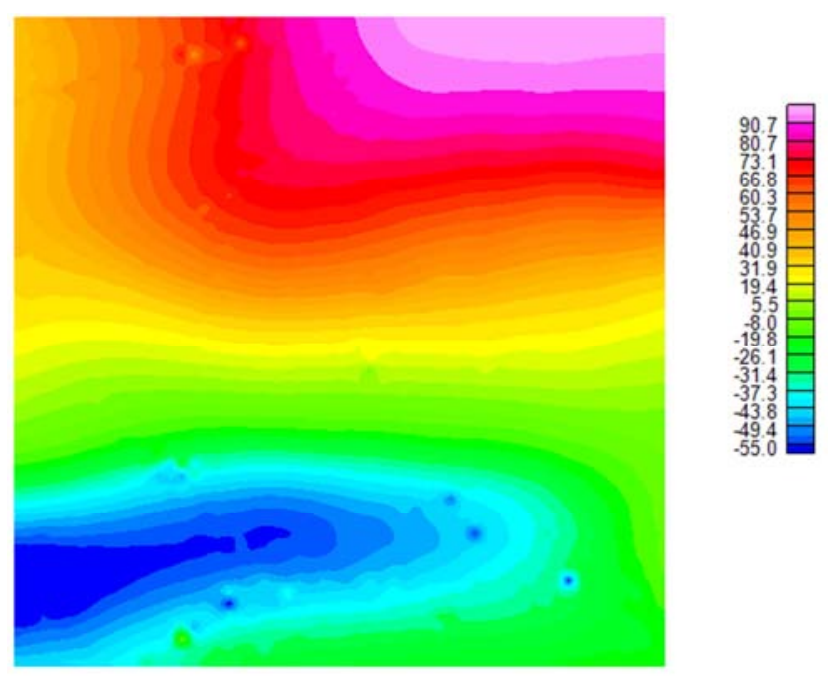

Figure 3. Aeromagnetic Raster Map of the Study Area (nT).
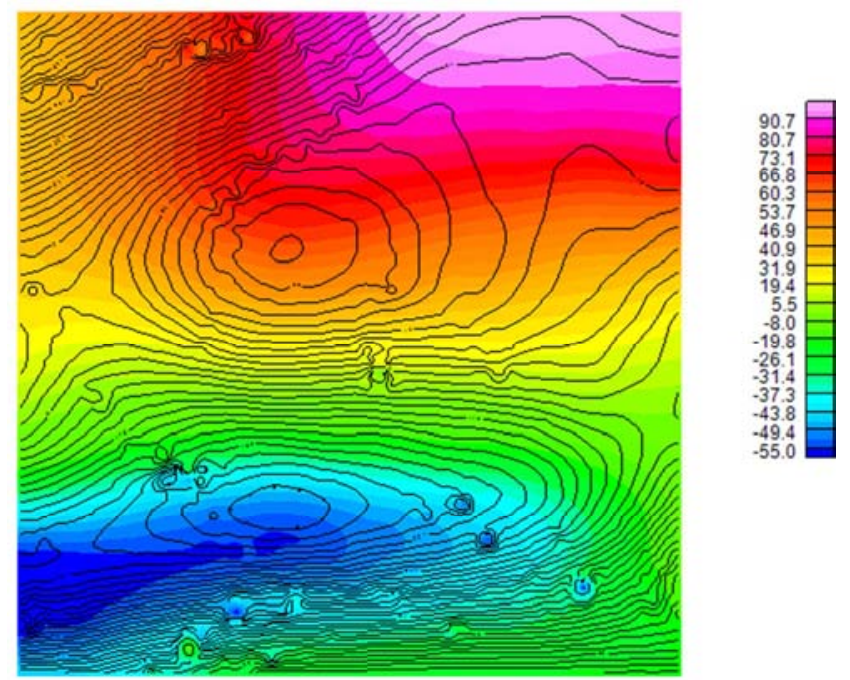

Figure 4. Aeromagnetic Contour Map of the Study Area (nT).

The regional map (Figure 5) is the qualitative effect of the regional - residual separation performed on the TMI map. The regional - map depicts zones with long wavelength and with $\mathrm{E}-\mathrm{W}$ tectonic trends. The regional aeromagnetic values range between- $57.1 \mathrm{nT}$ to $89.0 \mathrm{nT}$. The southern region is associated with low magnetic values (blue and green colours) while the northern portion of the map is marked with high aeromagnetic values (yellow, red and violet colours). 

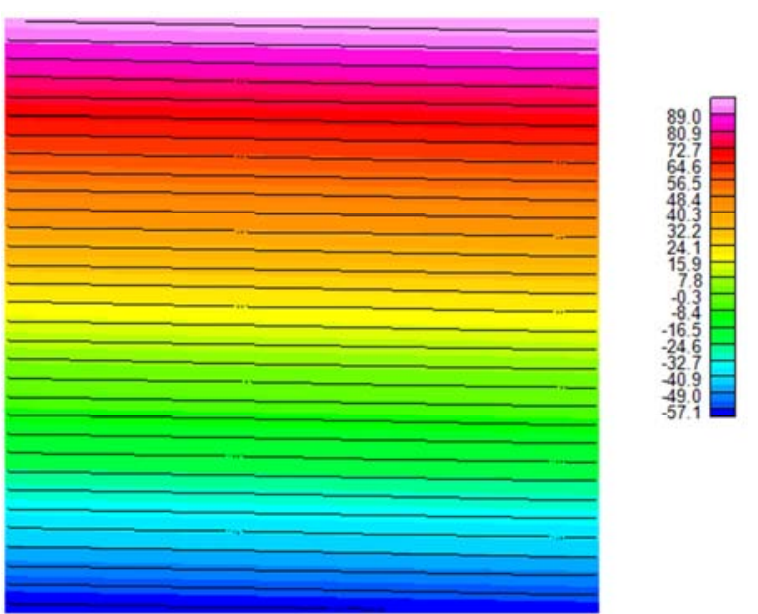

Figure 5. Regional Map of the Study Area (nT).

Like the regional map, the residual map (Figure 6) is the resultant effect of the regional - residual separation. The residual map enhanced the accentuation of shallow bodies. The residual anomalous map highlights short wavelength (high frequency) magnetic bodies' trending in the E - W and NE - SW directions at the southern and northern end of the map respectively. The aeromagnetic values range between$29.8 \mathrm{nT}$ and $21.5 \mathrm{nT}$.

As evidenced by the smoothness of the magnetic signatures, the residual map indicates a field which corresponds to the high pass filters and is indicative of local trend variations giving clues on structures for possible hydrocarbon, mineral or ore emplacement. The colour variations reveal two magnetic zones which can be grouped into magnetic high (blue and green colours) and magnetic low (yellow, red and violet colours)

Figure 7 exemplifies magnetic highs and lows using the arrow, straight and dash thick lines. Areas under the straight thick lines are the magnetic high zones and the areas under the dash thick lines represent the magnetic low. The single and double directional arrows indicate magnetic low but with the double line highlighting weathered magnetic zone. The double directional arrow under the magnetic high region is typical of magnetic aureole according to [16].
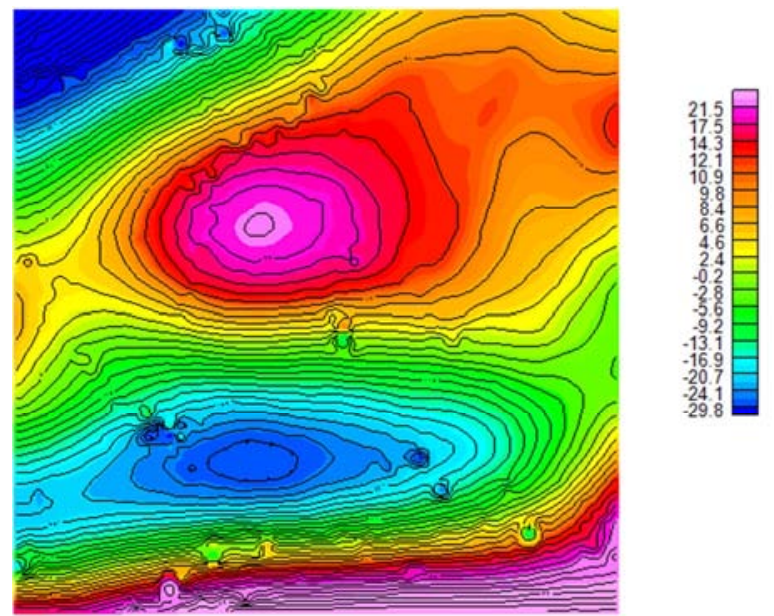

Figure 6. Aeromagnetic Residual Map of the Study Area (nT)
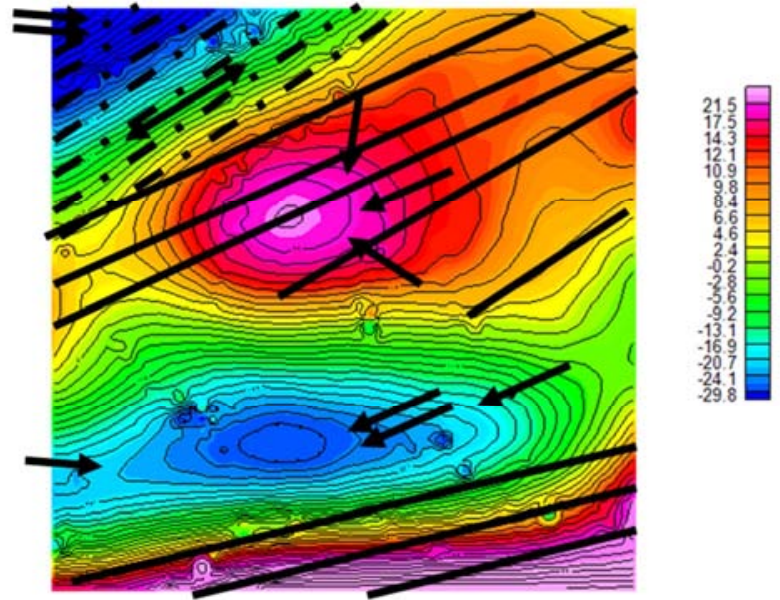

Figure 7. Aeromagnetic Residual Map of the Study Area Showing Magnetic Highs and Lows (nT).

The FVD map, shown in Figure 8, highlights shallow anomalous signatures. Similar to the residual map, the signatures trend in the $\mathrm{E}-\mathrm{W}$ and NE - SW directions at the southern and northern portion of the map respectively. The map shows smoothened contours with less noise effect. These magnetic contours are highly parked at the southern and north western part of the map.

Figure 9 reveals a higher derivative of the second vertical derivative of the aeromagnetic data. Analogous to the first vertical derivative, the second vertical derivative reveals changes in magnetic field in the vertical direction. Unlike the FVD map, the anomalies shown in the SVD map are of shorter wavelength. The short wavelengths or the high frequency components are true reflection of the shallow magnetic bodies. The anomalies trend in the NE - SW direction. However, fewer magnetic anomalies can be seen to be trending $\mathrm{E}-\mathrm{W}$ at the western and southern portion of the map. The numerous shallow anomalies occurring on the SVD map necessitated the zoning of the map into three magnetic units (of 1, 2 and 3) which is shown in Figure 10.
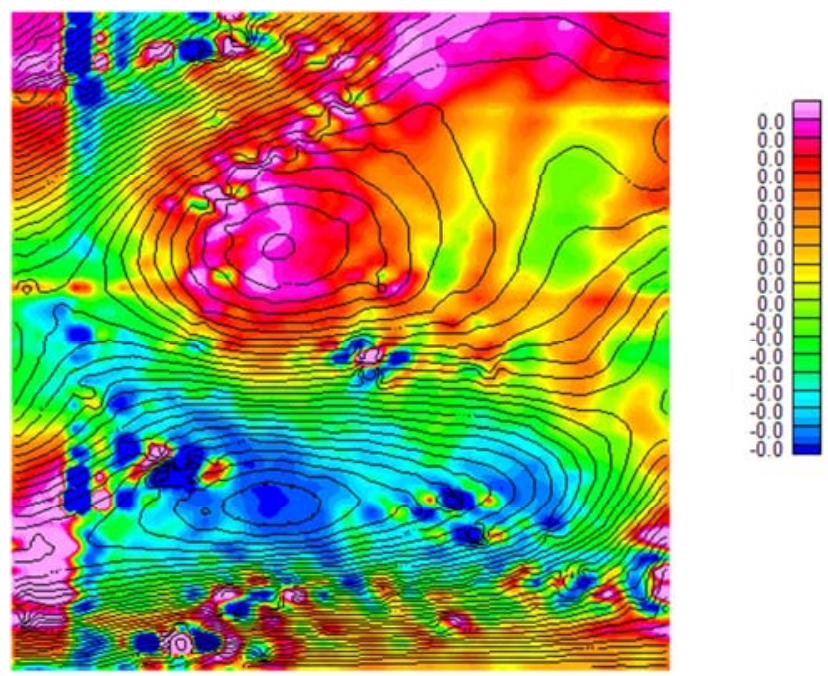

Figure 8. First Vertical Derivative Map (nT) 

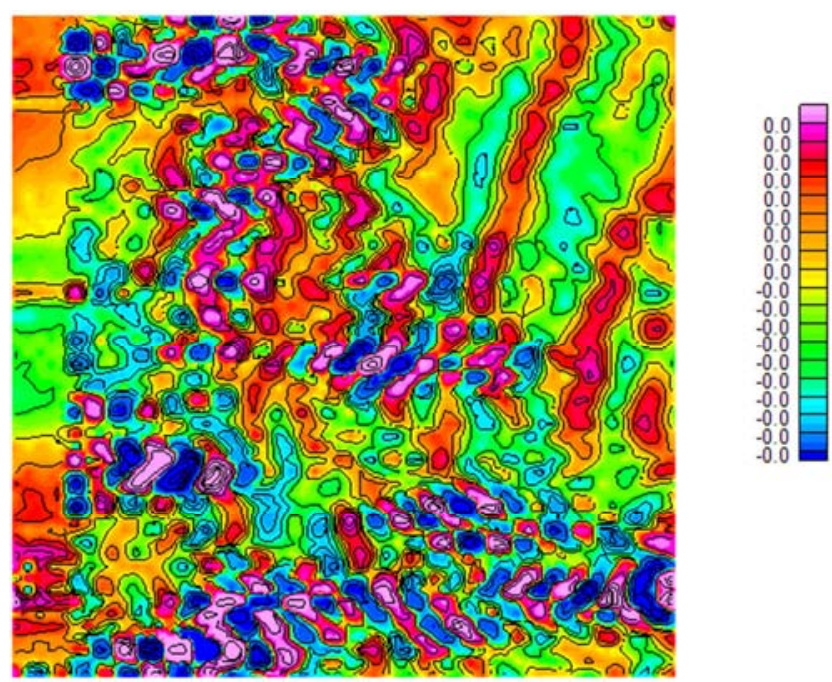

Figure 9. Second Vertical Derivative Map (nT).

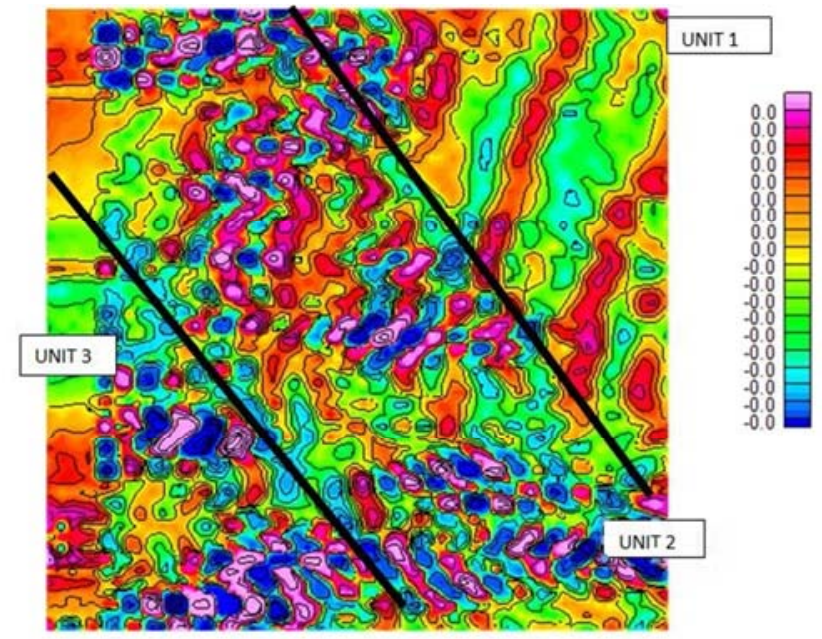

Figure 10. Second Vertical Derivative Map Sectioned into three identifiable Units of 1, 2 AND 3 (nT).
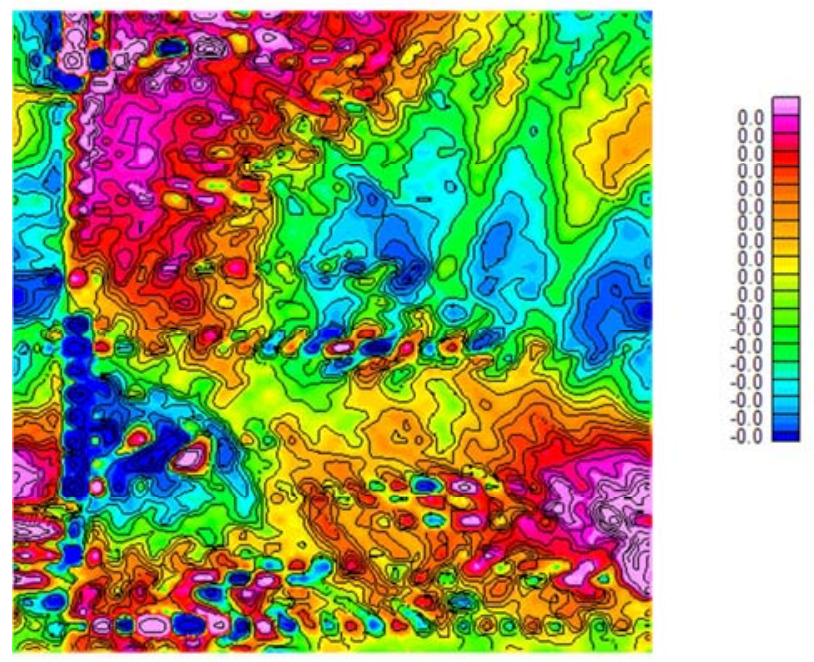

Figure 11. First Horizontal Derivative Map (nT).
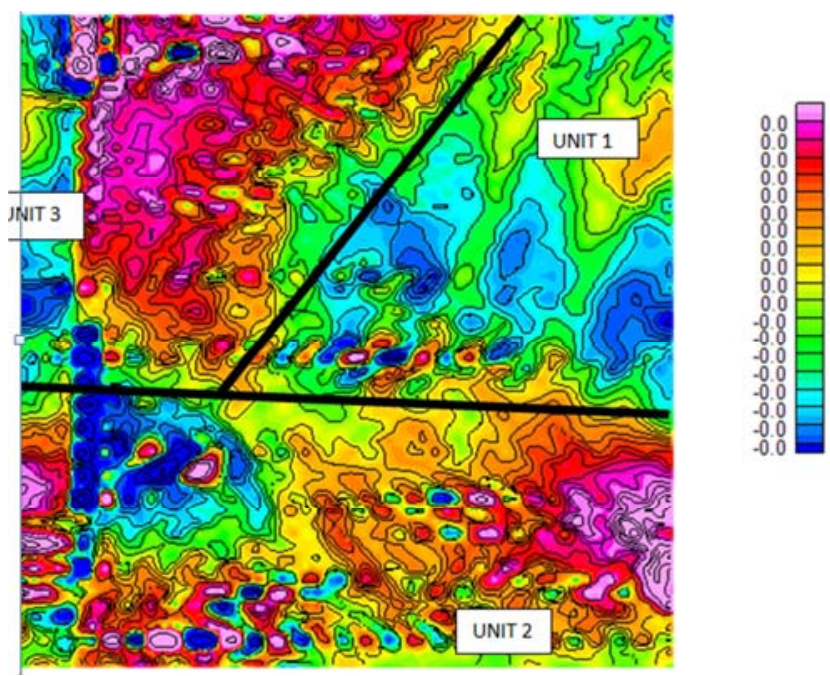

Figure 12. First Horizontal Derivative Map (nT).

The horizontal derivative map (Figure 11), unlike the FVD and SVD maps, shows variations in the magnetic field intensity in the horizontal direction. Subtle anomalous signatures trending in the E - W, NE - SW and NW - SE directions were revealed. These signatures have sharp edges like the anomalous features found in the vertical gradient maps. To further handle each of the numerous occurring short wavelength bodies, the FHD map was divided into three identifiable units on the bases of their magnetic intensity as shown in Figure 12.

\section{Discussion of Findings}

The aeromagnetic data covering parts of Degema, Rivers State, Nigeria was qualitatively produced into a map consisting of aggregate of colours called the composite total magnetic intensity (CTMI) map. By first inspecting the CTMI map, colour contrasts are apparent. These colour variations show the magnetic intensity values at various point of the map. The contrast in colour are possibly due to the presence of faults, fractures, dykes, seals, undulations in the basement, differences in lithology and geologic contact as well as magnetic susceptibility contrast of minerals present in the sedimentary section. The aeromagnetic raster map comprises of the violet, yellow, red, green, blue and the light blue colours. Beside the CTMI map is a corresponding legend showing positive and negative magnetic intensity values.

The negative values imply areas that are magnetically subdued or quiet while the positive values are magnetically responsive. In regards to the CTMI map, the magnetically subdued areas are the magnetic low points of the study area and this is typical of a sedimentary terrain while the magnetic responsive areas are the magnetic high regions which according to [17] is believed to be due to either igneous or metamorphic rocks. Based on the variation of intensity of magnetic responses, the magnetic low regions are discernible at the southern part of the map while the magnetic highs are obvious at the northern end of the map. The aeromagnetic 
intensity values ranges from- $55 \mathrm{nT}$ to $90.7 \mathrm{nT}$. Minimum intensity value of- $55 \mathrm{nT}$ occurs within the southern portion of the CTMI map while a maximum value of $90.7 \mathrm{nT}$ dominates the northern portion of the map. Critical examination of the magnetic low occurring at the southern portion of the map reveals the blue colour been embedded inside the light blue colour. [16] is of the opinion that the blue is as a result of the superposition of magnetic units while the light blue colour is as a result of weathering of the magnetic units.

The transformed contour map highlights contours of various characteristics. The magnetic contours vary from been closely parked, relatively closed, closed, linear, smooth to been parallel, elliptical, broadened and irregular. The CTMI is composed of residual and regional field effect trending in the NE - SW and E - W directions but with the NE - SW tectonic trends been dominant. The residual effects are masked on the regional effects and both effects are the result of total magnetization of rocks which indicate the whole sum of remnant and induced magnetization. The residual and regional anomalous effects are due to shallow magnetic bodies and deep seated magnetic bodies in the mantle and core, respectively. In order to unravel the tectonics and economic potential of the study area as the residual effect may provide evidence of the existence of mineral ore bodies or reservoir type sedimentary structures by highlighting some subtle or concealed features, regional residual separation becomes necessary.

The regional map reveals hidden and planar E - W tectonic trend which is economically insignificant in terms of both hydrocarbon and minerals. The regional field aeromagnetic values ranges from- $57.1 \mathrm{nT}$ to $89.0 \mathrm{nT}$ as depicted by the legend attached beside the map. However, values between$57.1 \mathrm{nT}$ to $15.9 \mathrm{nT}$ reflects magnetic low areas (blue and green colours) and this can be traced within the southern portion of the map. From the central portion of the map are high magnetic values represented with the yellow, red and violet colours. These magnetic high anomalies can be found from the central part of the map to the northern portion.

The residual anomalous map contains various contour configurations with high economic significance. They contours are of low amplitude and longer wavelength in nature. Although short wavelength magnetic sources are apparent on the map. Generally, the magnetic signatures trend in the NE - SW and E - W directions. More or less closely parked, circular, linear, parallel, broadened or localized contours are revealed on the residual map. Revealed at the northwestern part of the map after the regional - residual was carried out are low magnetic areas typical of a sedimentary section. These areas are indicated with the dash thick lines. Within the area are two magnetic lows, namely the area indicated with the double directional arrow and that indicated with thick double arrow points. The thick double arrow point highlighted closely parked, linear and parallel magnetic anomalies trending in the NE SW. The area under the two thick directional lines trend also in the NE - SW direction and is presumed to be possible structures housing hydrocarbon but Dobrin and Carl (1988) believe that this anomalous pattern results from subsurface faulting that have displaced magnetized rocks. This region falls under the Sombreiro- Warri Deltaic Plain (SDP) at Orerokpe in the western Niger Delta. Moving downwards and northeast wards are magnetic high which lies within the regional thick lines. The regions with high magnetic values are attributed to basement rocks that have intruded onto the sedimentary section. Geologically, the Benin Formation, SDP, Mangrove Swamps, Meander belt wooded back swamps (MWS) cut across this area. The magnetic high anomalies trend in the NE - SW direction. Within the region, circular and irregular magnetic contours are conspicuous. Higher magnetic anomaly occurs visibly at the circular magnetic contour indicated with three directional arrows. The high magnetic values surrounded by the closer circular contour are perceived to be magnetic aureole and this is indicative of high tectonics within such region but [16] opines that the circular anomalies are due the accumulation of magnetite. Further away from the magnetic aureole and moving north eastwards, the contours are farther apart. Generally, the closely parked and spaced contours found within the magnetic high and low areas indicate shallower and deeper anomalous sources respectively. Immediately below the magnetic highs are linear magnetic signatures which are of regional extent and which trends in the $\mathrm{E}-\mathrm{W}$ direction. [17] believe that the $\mathrm{E}$ W directional trend is typical of Pre - Pan African trending fault characterized by little brittle deformation which resulted in the development of conjugate strike - slip fault systems while [18] stated that the E - W anomaly is typical of the anomaly induced around the equator where the field is horizontal. According to [19], the E - W trend often coincides with litho - tectonic domains. Nevertheless, they linear signatures are of low relief and long wavelength. Moving further southward is an anomalous low with single and double arrow. This magnetic anomaly has a short wavelength and low relief as well as an elliptical shape. The elliptical nature signifies a dyke that houses hydrocarbon. An almost NE - SW trend lies below the dyke like structure. The NE - SW trend probably indicates the Charcot fault and chain oceanic fracture zones which serve as a migratory path for hydrocarbon. Hence the possibility of the NE - SW trend in aiding the exportation and importation of hydrocarbon from the dyke cannot be over ruled. Above all, high magnetic anomalies trending in the $\mathrm{E}-\mathrm{W}$ directions are discernible at the northern extreme part of the map.

The first vertical derivative (FVD) map shows smoothened shallow magnetic bodies with anomalous trend of E - W and NE - SW. Unlike the residual map, high magnetic values indicating magnetic intrusions occur at the north western and south western portion of the map when the enhancement technique was applied. However, zones with high aeromagnetic values can also be seen obviously at the northern and slightly at the southern portion of the map. As earlier stated, the high values are intrusions upon the sedimentary cover. Little magnetic low 
points can be sighted at the north western and southern areas. The contour obtained during the FVD transformation bears the same configuration with the residual map. This therefore implies that the magnetic sources can still be located at the same depth after the FVD filtering action.

Second vertical derivative map reveals irregular magnetic signatures of shorter wavelength unlike in the FVD. The SVD magnetic field map contains anomalies and magnetic discontinuities with E - W, NE - SW and subtle NW - SE structural trends. Thus, it can be said that the major $\mathrm{E}-\mathrm{W}$ and NE - SW trends truncated an older NW - SE trend within the area. To handle effectively the various magnetic anomalies and to identify the possible hydrocarbon and other mineralized structures occurring within the study area, the SVD map was divided into three identifiable magnetic units. The Magnetic units were established based on dominant magnetic signatures and patterns of the anomalies. Unit 1, 2, 3 are located at the North northeast, central and south western portion of the map. Unit one covers about twenty five percent $(25 \%)$ of the map and is located at the north - northeast part of the study area. The unit is characterized with irregular magnetic highs and lows having a general axis trend of NE - SW. Magnetic high occupies the northern, eastern and southern portion of unit one while the magnetic low occupies the central portion of the unit. Within the unit, they anomalies are of longer wavelength and it can be seen that the edges of the anomalies with high values cut across the boundary of unit one and two. Magnetic unit 2 is emplaced centrally and occupies about fifty percent $(50 \%)$ of the map. Unit 2 consists of mixture of irregular magnetic highs and lows. The anomalies are almost of equal wavelength except for the anomalies found at the northwestern portion of the unit. The anomalies generally trend in the NE - SW and NW - SE direction. Few E - W tectonic trends can as well be seen at the North western portion of the map. Unit 3 is located at the south western portion of the map and it occupies about twenty five percent $(25 \%)$ of the map. The region is characterized with equal number of magnetic highs and lows but with the magnetic low dominating. The anomalies trend in the NE - SW, NW - SE and E - W but with the E $\mathrm{W}$ trend been less occurring at the western portion of the unit. Generally, keen inspection of the SVD map reveals short wavelength bodies with blue and green colouration across all the magnetic units. The blue and green magnetic bodies are typical of a sedimentary terrain and they signify probable structures that could accumulate hydrocarbon. It could therefore be inferred that the percentage of hydrocarbon accumulation and exploration would be on the increase within the study area as the intrusive which will be a suitable source of geothermal energy are in proportion with the magnetic lows. The intrusive will provide appropriate geothermal energy needed for the maturation of source rocks.

Like the SVD map, the horizontal derivative map attenuates long wavelength and provides magnetic bodies with short wavelength and sharp edges. Based on the magnetic intensities of the anomalies, FHD map was divided into three identifiable units like the SVD. The division was done so as to handle each of the numerous occurring short wavelength bodies. About thirty percent $(30 \%)$ of the map is covered by unit one. Magnetic unit one is characterized majorly by irregular magnetic lows trending in the NE - SW direction. However, little magnetic high can be seen at the eastern and northern portion of the unit. Magnetic unit 2 covers about thirty five (35) of the FHD map. Shorter wavelength of magnetic highs and lows are apparent within the unit. This unit comprises of anomalies trending in the N-S, E - W, NE - SW and NW SE direction. Short wavelength magnetic low occurs at the north - western portion of the unit while magnetic high occurs at the western, southern and majorly at the eastern portion of the unit. Unit 3 comprising majorly of magnetic high cover about thirty five (35\%) of the map. Positioned at the eastern, southern and western portion of the unit are magnetic lows. The anomalies trend in the E - W, NE - SW, NW - SE direction. The wavelength of the anomalies are comparable to that is observed in unit 2 but lesser than the wavelength of anomalies in unit one.

\section{Conclusion}

Probable structures which have effect on hydrothermal fluid migration were exhumed within the study area using the qualitative approach. These structures trend in the $\mathrm{E}$ W, N - S, NW - SE, NE - SW directions but with the E - W trends being dominant. The elongated $\mathrm{E}-\mathrm{W}$ trends, however, serve as a migratory path. The persistent elongated structure with light blue colouration at the eastern portion of the study area denotes a dyke or a potential source rock. The maturation of the source rocks will be fostered by the possible igneous body found at the northern portion of the map. Hence, the study area becoming viable economically. Nevertheless, the qualitative analysis performed upon the HRAM data conform favourably with the result of other researchers within the area of study in that these structures aid the migration and entrapment of hydrocarbon with the aid of elongated linear structures and near circular bodies respectively.

\section{References}

[1] Mariita, N. O. (2007): The magnetic method. Presented at Short Course II on Surface Exploration for Geothermal Resources, organized by UNU - GTP and Ken Gen, at Lake Naivasha, Kenya, 1 - 8.

[2] Henry, L. (2010): Magnetic and Gravity Methods in Mineral Exploration: the Value of Well - Rounded Geophysical Skills. CSEG recorder, 27(2), 31 - 35.

[3] Jose, R. (2009): Gravity and magnetic methods: Presented at "Short Course on Surface Exploration for Geothermal Resources", organized by UNU - GTP and La Geo, in Ahuachapan and Santa Tecla, El Salvador, 1 - 13. 
[4] Micahel, D. and Steven, M. (2014): Geophysics for the Mineral Exploration Geoscientist $\left(1^{\text {st }}\right.$ edn). Cambridge University Press, New York. 86 - 88.

[5] Abdusalam, N. N., Mallam A., and Likkason, O. K. (2011): Evidence of some tectonic events in the Koton Kaifi area, Nigeria, from aeromagnetic studies. Journal of petroleum and gas exploration research, 3 (1), 7 - 15.

[6] Emujakporue, G and. Ofoha, C. (2015). Qualitative interpretation of aeromagnetic data of parts of offshore Niger Delta, Nigeria. Scientia Africana, 14(1), 40 - 54.

[7] Fairhead, J. D. (2012): Regional tectonics and basin formation: The role of potential field studies in Phanerozoic. Regional Geology of the world, 12 (2), 330 - 341.

[8] Aizebeokhai, A. P. and Olayinka, I. (2011): Structural and stratigraphic mapping of Emi field, offshore Niger Delta. J. Geol. Min. Res., 3(2), 25 - 38.

[9] Oladele, S. and Ojo, B. (2013): Basement Architecture in Part of the Niger Delta from Aeromagnetic Data and its Implication for Hydrocarbon Prospectivity. The Pacific Journal of Science and Technology, 14(2), 512 - 520.

[10] Okiwelu, A. A., Obianwu, V. I., Eze, O., and Ude, I. A. (2012): Magnetic anomaly patterns, fault block tectonism and hydrocarbon related structural features in the Niger Delta basin. Journal of applied geology and geophysics, Vol 2, Issue 1 Ver. 1,31 - 46.

[11] Doust, H., and Omatsola, E. (1990): Divergent passive Margin Basin, AAPG Memoir 48. American association of Geologists, 48:42-55.
[12] Li, Y. and Oldenburg, W. (1998): Separation of regional and residual magnetic field data. Geophysics, 63 (2), 431 - 439.

[13] Phillips, J. D. (2002). Two - step processing for 3D magnetic source locations and structural indices using extended Euler or analytic signal methods: 72nd Ann. Internat. Mtg. Soc. Expl. Geophys, Expanded Abstracts, GM 1. 5. 2 - 7.

[14] Luis, A. M. (2009): Processing techniques of aeromagnetic data: Case studies from the Precambrian of Mozambique. M. sc thesis, Uppsala university, Mozambique, (Publ).

[15] Blakely, R. J. (1996): Potential theory in gravity and Magnetic Applications. Cambridge University Press, New York, 435 567.

[16] Gunn, P. J., Maidment, D. and Milligan, P. R. (1997): Interpreting aeromagnetic data in areas of limited outcrop. Journal of Austrian Geology and Geophysics, 17(2), 175 185.

[17] Onuba, L. N., Anudu, G. K., Chiaghanam, O. I. and Anakwuba, E. K. (2011). Evaluation of Aeromagnetic Anomalies Over Okigwe Area, South - eastern Nigeria. Research Journal of Environmental and Earth Sciences 3(5): $498-507$.

[18] Stone, V., Fairhead, J. D., Oterdoom, W. H. and Carigali, P. (2004): The meter reader: Micro magnetic seep detection in the Sudan. The Leading Edge, 23(8): 734-737.

[19] Jiakang, L. and Igor, M. (2005): Potential Field investigation of Williston Basin Basement. Canadian Society of Exploration Geophysicists National Convention, pp. 75-76. 